\title{
Eficácia da estufa de Pasteur \\ como equipamento esterilizante \\ em consultórios odontológicos*
}

\section{Solange do Socorro Fonseca Tavares ${ }^{1}$, Joaquim Tomé de Sousa ${ }^{2}$, Anaclara Ferreira Veiga Tipple ${ }^{3}$, Adenícia Custódia Silva e Souza ${ }^{4}$, Fabiana Cristina Pimenta ${ }^{5}$, Patricia Staciarini Anders ${ }^{6}$}

\section{RESUMO}

Este estudo objetivou avaliar a eficácia do uso da estufa de Pasteur, como equipamento esterilizante, em consultórios odontológicos, por meio de monitoramento biológico. Para esta avaliação foram consideradas: adequação no carregamento dos materiais no equipamento, tempo/temperatura utilizados e manutenção preventiva da estufa. Os dados foram coletados em 101 consultórios odontológicos, no Distrito Central de Goiânia-GO, Brasil, por meio de observação, entrevista e realização de teste com indicador biológico. Os resultados demonstraram não-padronização de algumas condutas preconizadas pelo Ministério da Saúde (MS), para esterilização dos artigos em estufa, e positividade do teste biológico em $46(45,5 \%)$ dos ciclos testados. Os fatores intervenientes, com maior significância, relativos às falhas da esterilização foram: ausência do termômetro acessório para o controle da temperatura dos ciclos e a inobservância das relações tempo/temperatura recomendados para o ciclo de esterilização, por calor seco.

\section{DESCRITORES}

Controle de infecções dentárias.

Esterilização.

Controle de qualidade.

\begin{abstract}
This study was aimed at assessing the efficacy of the use of the Pasteur oven as sterilization equipment in dental offices through biological monitoring. For this assessment were taken into account how adequately the material is loaded into the equipment; time/temperature used; and preventive maintenance of the oven. The data were collected in 101 dental offices in the Central District of Goiânia, in the State of Goiás, through observation, interviews and performance of tests with biological indicator. The results showed a lack of standardization of some of the procedures recommended by the Ministry of Health for sterilization of items in the oven, and positive results of the biological test in 46 (45.5\%) of the tested cycles. The intervening factors with most significance regarding sterilization problems were: absence of an accessory thermometer to control the cycles' temperature and non-observance of the time/temperature relations recommended for the sterilization cycle through dry heat.
\end{abstract}

\section{KEY WORDS}

Infection control, dental.

Sterilization.

Quality control.

\section{RESUMEN}

Este estudio tuvo como objetivo evaluar la eficacia de la estufa de Pasteur, como equipamiento esterilizante, en consultorios odontológicos, por medio del monitoreo biológico. Para esta evaluación se consideraron: adecuación en el cargamento de los materiales en el equipamiento, tiempo/temperatura utilizados y mantenimiento preventivo de la estufa. Los datos fueron obtenidos en 101 consultorios de odontología, en el Distrito Central de Goiânia-Goiás-Brasil, por medio de la observación y la entrevista, así como la realización de un test con indicador biológico. Los resultados demostraron la no patronización de algunas conductas preconizadas por el Ministerio de Salud (MS), para la esterilización de los artículos en estufa, y la prueba biológica positiva en $46(45,5 \%)$ de los ciclos probados. Los factores de mayor intervención significativa, relativos a las fallas de la esterilización fueron: ausencia del termómetro accesorio para el control de la temperatura de los ciclos y la no observación de las relaciones tiempo/ temperatura recomendadas para el ciclo de esterilización, por el calor seco.

\section{DESCRIPTORES}

Control de infección dental.

Esterilización.

Control de calidad.

\footnotetext{
* Extraído da dissertação "Avaliação da eficácia da estufa de Pasteur como equipamento esterilizante em consultórios odontológicos do Distrito Central de Goiânia-GO", Faculdade de Enfermagem, Universidade Federal de Goiás, 2005. 'Enfermeira. Mestre em Enfermagem pela Faculdade de Enfermagem, Universidade Federal de Goiás (UFG). Goiânia, GO, Brasil. sulaftavares@uol.com.br ${ }^{2}$ Médico. Professor Doutor da Faculdade de Enfermagem, Universidade Federal de Goiás (UFG). Goiânia, GO, Brasil. tome@superig.com.br ${ }^{3}$ Enfermeira. Professora Doutora da Faculdade de Enfermagem, Universidade Federal de Goiás (UFG). Goiânia, GO, Brasil. anaclara@fen.ufg.br ${ }^{4}$ Enfermeira. Professora Doutora da Faculdade de Enfermagem, Universidade Federal de Goiás (UFG). Goiânia, GO, Brasil. adenicia@fen.ufg.br ${ }^{5}$ Farmacêutica.Professora Doutora do Instituto de Patologia Tropical e Saúde Pública (IPTSP-UFG). Goiânia, GO, Brasil. pimenta@iptsp.ufg.br ${ }^{6}$ Enfermeira. Mestre em Microbiologia pelo Instituto de Patologia Tropical e Saúde Pública (IPTSP-UFG). Goiânia, GO, Brasil. pstaciarini@hotmail.com
} 


\section{INTRODUÇÃO}

A prática da Odontologia abrange inúmeros procedimentos, que incluem desde simples exames clínicos a cirurgias complexas. Durante o seu exercício, agentes infecciosos podem ser transmitidos aos pacientes e profissionais por diferentes vias: contato direto com lesões infecciosas, sangue e saliva contaminados; contato indireto, mediante transferência de microrganismos presentes em objetos contaminados; respingos de sangue, saliva e/ou secreções nasofaríngeas, diretamente em feridas de pele e mucosa; e pela transferência de microrganismos por aerossóis $^{(1)}$

Apesar de grande parte das infecções relacionadas à assistência a saúde serem causadas por microrganismos da microbiota do próprio indivíduo, as infecções de origens exógenas merecem a atenção dos profissionais de saúde. A inobservâncias das boas práticas de prevenção e controle de infecção são as principais responsáveis pelas iatrogenias infecciosas de origem exógena ${ }^{(2)}$.

Artigos odonto-médico-hospitalares podem servir como veículos na transmissão de agentes infecciosos para hospedeiros suscetíveis, sendo a esterilização comprovadamente um método eficiente para o controle da contaminação cruzada e a autoclavação, com vapor de água saturado e sob pressão, o método que oferece maior segurança ${ }^{(3)}$.

Esterilização é a completa eliminação ou destruição de todas as formas de vida microbiana ${ }^{(4)}$ podendo ser feita por meio de processos físicos, químicos ou físico-químicos automatizados, sendo os principais: processos físicos - vapor saturado sob pressão (autoclave), calor seco (estufa) e radiação (raios gama-cobalto 60); processos químicos - grupo dos aldeídos e ácido peracético; processos físico-químicos automatizados - óxido de etileno, plasma peróxido de hidrogênio e por vapor a baixa temperatura e formaldeído ${ }^{(1-2)}$.

A escolha do tipo de reprocessamento de um artigo de múltiplos usos depende da natureza do material a ser esterilizado. A classificação proposta por Earle Spaulding, em 1968, continua a ser utilizada, e determina os métodos de reprocessamento de artigos, para o reuso em clientes ${ }^{(1,3-5)}$.

Um estudo(6), apresentou uma adaptação da classificação de Earle Spaulding aos artigos odontológicos: artigos críticos - entram em contato com tecidos estéreis ou sistema vascular, necessitam ser esterilizados ou descartados (ex.: instrumentais cortantes, brocas, agulhas, limas, canetas de alta rotação, raspadores periodontais); artigos semicríticos - entram em contato com membranas mucosas e peles não íntegras, necessitam de desinfecção de alto nível, esterilização ou descartados (ex.: abridores de boca, arcos para isolamento absoluto) e os não-críticos em: artigos com contato intraoral (ex.: moldeiras, próteses, aparelhos ortodônticos) e em contato com pele íntegra (ex.: arcos faciais ortodônticos), sendo a desinfecção de nível intermediário indicada para ambos.

Sempre que a literatura aborda aspectos do reprocessamento de artigos, para o manuseio da cavidade oral, preconiza a esterilização. Isto se justifica pela particularidade do atendimento odontológico, pois é difícil garantir que um artigo semicrítico ou até não-crítico não se transforme em crítico, durante o procedimento ${ }^{(3)}$.

Apesar da estufa (forno de Pasteur) ser o método mais popular, para esterilização de artigos, entre os CirurgiõesDentistas (CD), acredita-se que muitos a operacio-nalizam de forma incorreta, visto constituir-se de um equipamento cujo processo requer o controle de diversas variáveis ${ }^{(3)}$. As falhas mais freqüentes no reprocessamento de artigos em estufas são: tempo de esterilização insuficiente; aferição da temperatura somente pelo termômetro do próprio aparelho; interrupção do ciclo de esterilização pela abertura da estufa, para colocação ou retirada de artigos; instrumentais inadequadamente limpos e úmidos; caixas metálicas, contendo grande quantidade de instrumental; embalagens colocadas incorretamente no interior da estufa dificultando a circulação do ar quente e sobrecarga de mais de $80 \%$ da capacidade da estufa ${ }^{(2,7)}$. A não-validação dos processos, o uso de temperatura fora da padronização e de recipientes de aço inoxidável, que dificultam a condução do calor são outras possíveis falhas.

Considerando-se que a esterilização é importante medida de proteção antiinfecciosa $a^{(1,3-5,5)}$, e devido ao uso freqüente da estufa como equipamento esterilizante, na área odontológica, empreendeu-se o desenvolvimento deste estudo com o objetivo de avaliar a eficácia da estufa de Pasteur, como equipamento esterilizante, em consultórios odontológicos e caracterizar os responsáveis pelo reprocessamento dos artigos odontológicos quanto a formação, ao nível de escolaridade, ao sexo e a idade.

\section{MÉTODO}

Estudo descritivo analítico realizado em consultórios odontológicos particulares, localizados no Distrito Sanitário Central do Município de Goiânia - GO, no período de março de 2004 a janeiro de 2005. Elegemos esse distrito, para a realização do estudo, porque dentre os 1.870 consultórios odontológicos nos onze distritos do Município de Goiânia, o distrito central compreendia 53\% do total de consultórios com alvarás de licença sanitária. Considerando estes dados e o teste piloto, o cálculo amostral definiu um número de 101 consultórios e a determinação da amostra foi aleatória, observando a proporcionalidade, por bairro. 
Durante a realização do estudo, houve fiel observância aos aspectos éticos da pesquisa ${ }^{(9)}$, com aprovação por um Comitê de Ética, protocolo no. 010/03, consentimento dos sujeitos envolvidos (responsável técnico pelos consultórios e/ou pelo reprocessamento dos artigos), e encaminhamento dos laudos aos responsáveis técnicos. Foram realizadas visitas prévias para agendamento da coleta, nos estabelecimentos que continham estufa como equipamento esterilizante. Procedeu-se a coleta de dados pela observação direta da operacionalização de um ciclo de esterilização registrado em um check-list, aplicação de entrevista com dados de caracterização do responsável pelo reprocessamento e descrição da prática do uso da estufa, aferição da temperatura (termômetro acessório da marca Incoterm ${ }^{\circ}$ ) e realização do teste de esterilização, com indicador biológico Bacillus subtilis.

Os procedimentos microbiológicos descritos a seguir foram realizados com o apoio técnico-científico do Laboratório de Bacteriologia Médica do Instituto de Patologia Tropical e Saúde Pública (IPTSP) da Universidade Federal de Goiás (UFG).

Os indicadores biológicos foram preparados pela impregnação de esporos do Bacillus subtilis (ATCC 6633) em barbantes esterilizados, com inoculo de $10^{6}$ contidos num tubo teste. Estes foram fixados externamente com fita crepe em uma das caixas de instrumental de uma carga de esterilização e posicionados no centro da estufa (ponto frio)(10), embora a recomendação seja colocá-los na parte interna dos pacotes ${ }^{(7)}$. Procedeu-se desta maneira, para não interferir na dinâmica da esterilização de cada consultório e na demanda do material para os atendimentos. Diante deste fato, considerou-se que essa conduta poderia pressupor resultados falsos negativos, porém não invalidaria o estudo.

Após a realização das coletas, encaminhava-se o tubo de ensaio, em container térmico, ao laboratório. Procedia-se a análise microbiológica, da seguinte maneira: vertiam-se $5 \mathrm{~mL}$ de caldo $\mathrm{BHI}$, no tubo de ensaio, contendo o barbante teste, incubando-o em banho-maria a $37{ }^{\circ} \mathrm{C}$, por 07 dias. Transcorrido este período, para o tubo-teste que apresentasse turvação, preparava-se uma lâmina realizando a coloração pelo método de Gram, para confirmação da morfologia dos bacilos/esporos.

Após os resultados, laudos foram emitidos e encaminhados aos respectivos responsáveis técnicos, pelos estabelecimentos odontológicos, ocasião em que era entregue um roteiro, constando orientações, para o reprocessamento de artigos odontológicos.

Os dados foram organizados e tabulados no software estatístico EPI INFO, versão $3.2^{(11)}$ Utilizou-se o Teste $c^{2}$, para a análise das variáveis nominais intervenientes na positividade do teste biológico com o Bacillus subtilis. As variáveis foram: o acondicionamento da carga, o tempo e a temperatura utilizados, o uso de testes químicos no con- trole da esterilização, a prática da manutenção preventiva, e a realização do teste biológico, como parâmetro de qualidade. Valores de $p<0,05$ foram considerados estatisticamente significantes.

\section{RESULTADOS E DISCUSSÃO}

No estudo, foram encontradas as seguintes especialidades de atendimento odontológico: Clínica Geral, Prótese, Ortodontia, Endodontia, Implantodontia, Odontopediatria, Dentística, Periodontia e Odontogeriatria. Em todas, observou-se a utilização de artigos críticos cujo método de escolha para a esterilização deveria ser o vapor saturado sob pressão (autoclave), por serem termorresistentes $^{(12)}$. Dos 101 consultórios que realizavam o processo de esterilização, em estufa, $62(61,4 \%)$ o faziam somente em estufa, $29(28,7 \%)$ em estufa e autoclave horizontal de mesa e $10(9,9 \%)$ em estufa e autoclave vertical. Constatou-se que $39(38,6 \%)$ consultórios utilizavam a estufa, para esterilização de artigos mesmo possuindo autoclave. $O$ uso do vapor saturado sob pressão, na maioria das vezes, era destinado somente para esterilização de artigos como: gazes, algodão, brocas de polimento e moldeiras de material plástico.

Em todos os consultórios, os profissionais que realizavam o reprocessamento dos artigos odontológicos, responderam as entrevista, sendo $21(20,8 \%) C D, 12(11,9 \%)$ auxiliares de cirurgiões dentistas (ACD), três $(3,0 \%)$ técnicas de enfermagem (TE), duas $(2,0 \%)$ técnicas em higiene dental (THD) e uma (1,0\%) ACD/TE. Em 62 (61,3\%) dos consultórios investigados, o profissional que realizava o reprocessamento dos artigos odontológicos não possuía formação profissional específica, na área da saúde, sendo uma trabalhadora do serviço de higienização e limpeza e as demais recepcionistas. As idades variavam entre 17 e 65 anos, com predomínio do sexo feminino $(87,1 \%)$ e escolaridade entre $\circ 1^{\circ} \mathrm{grau}$ incompleto e pósgraduação.

Considerando a importância do reprocessamento seguro dos artigos na prevenção das infecções e que estes devem obedecer aos critérios preconizados pelos órgãos normativos ${ }^{(1,8,12-13)}$, o predomínio de trabalhadores sem formação profissional na área da saúde reprocessando artigos odontológicos, encontrado neste estudo, é preocupante. $O$ despreparo do trabalhador para o reprocessamento de artigos implica em imperícia, negligência e/ ou imprudência, colocando em risco a qualidade do atendimento prestado ao cliente ${ }^{(14)}$. Em uma investigação conduzida por Tipple e seus colaboradores, em 2004, foi evidenciado que em 29 Centros de Saúde da rede Municipal de Goiânia, o reprocessamento de artigos odontológicos era executado, predominantemente, por ACD (48\%) e THD (21\%), contudo em nove unidades, esta era uma atribuição de trabalhadores sem formação na área da saúde, sendo que destes, três eram do quadro do serviço de higienização e limpeza ${ }^{(15)}$. 
Observou-se uma diversidade de artigos submetidos à esterilização, em estufa, nos consultórios odontológicos, predominantemente, instrumentais em $95(94,1 \%)$ dos consultórios, incluindo os artigos de corte, dentre eles: os de dentística, endodontia, periodontia e ortodontia. Em $79(78,2 \%)$ consultórios as estufas eram utilizadas, também, para a esterilização de brocas. Tais usos da estufa, são indicações dos $\mathrm{CDC}^{(8)}$.

O Ministério da Saúde preconiza a estufa de Pasteur como equipamento esterilizante, para os seguintes materiais e instrumentais: brocas, instrumental de endodontia, moldeiras resistentes ao calor, instrumentais de aço, bandejas e caixas metálicas, discos e brocas de polimento, placas e potes de vidro ${ }^{(1)}$. Constatou-se igualmente o uso da estufa, para a esterilização de gazes em $48(47,5 \%)$ consultórios, algodão em $33(32,7 \%)$ e cones de papel em um $(1,0 \%)$, contrariando as recomendações. Pano, papel, algodão e borracha não devem ser esterilizados, em estufa, porque não são bons condutores de calor, queimam as fibras e perdem a capacidade de absorção. Cones de papel devem ser esterilizados preferencialmente em autoclave, pois na estufa perdem parcialmente o seu poder de absorção(13). Na prática, estas conseqüências não são observadas, provavelmente, pela não-utilização da temperatura indicada ou pela diminuição do tempo de exposição preconizado.

Observou-se que 46 (45,5\%) dos consultórios utilizavam invólucros recomendados para o uso em estufa, como: caixa metálica fechada, papel alumínio e vidro refratário(12). Embora, as embalagens de aço inoxidável sejam oficialmente recomendadas, um autor ${ }^{(10)}$ alertou que elas não são boas condutoras de calor.

Chama a atenção, o fato da maioria dos consultórios, 55 (54,5\%) utilizarem condutas contraindicadas quanto às embalagens, como: uso de bandejas, sem invólucros, (denominadas cubetas que seriam utilizadas para a montagem de kits de instrumental estéril nos diferentes atendimentos), instrumentos soltos, nas prateleiras, e uso de papel pardo. Artigos críticos devem ser embalados, para que a esterilidade seja garantida, durante o transporte, armazenamento e até o uso, assim como favorecer a abertura asséptica, sem risco de contaminação do conteúdo ${ }^{(16)}$. Encontrou-se também papel alumínio, porém perfurado, comprovando sua restrição de uso, para determinados tipos de instrumental ${ }^{(2,12)}$.

O monitoramento do processo de esterilização deve incluir uma combinação de indicadores, químicos, biológicos e controles físicos, que avaliem as condições de esterilização e a eficácia do ciclo de esterilização(4). Quanto ao monitoramento químico e biológico constatou-se o descumprimento desses importantes parâmetros de qualidade do processo de esterilização, em estufa, nos consultórios odontológicos estudados.
Existem indicadores químicos (IQ) de alta especificidade e sensibilidade, para monitorar o processo de esterilização, pelo vapor saturado sob pressão, (autoclave). Contudo, para a estufa de Pasteur os indicadores disponíveis no mercado nacional não conferem a mesma segurança. Estão apenas disponíveis os IQ para uso externo, (classe I), indicadores de processo, que diferenciam os artigos submetidos à esterilização dos não reprocessados e os indicadores internos (classe III) que monitoram o alcance da temperatura, com viragem cinco minutos após a câmara atingir $170^{\circ} \mathrm{C}^{(2)}$.

É preocupante, a não-utilização dos indicadores químicos disponíveis comercialmente. Embora o uso destes indicadores não prove que a esterilização tenha ocorrido, permite evidenciar problemas de funcionamento no equipamento ${ }^{(8)}$.

Para o monitoramento biológico do processo de esterilização, por calor seco, são utilizados indicadores de primeira geração em forma de tiras de papel impregnado com $10^{6}$ esporos de Bacillus subtilis. Estão disponíveis, no mercado, e dão resultados pela leitura do teste, após sete dias ${ }^{(7)}$. Deve ser usado em estufa, quando da sua instalação, após cada manutenção corretiva e semanalmente. Comprova-se a capacidade esterilizante do equipamento pela morte de todos os esporos do indicador biológico (IB), usado para o teste ${ }^{(17)}$.

Nos parâmetros físicos do processo de esterilização, em estufa, devem ser observados: carregamento da estufa com preenchimento de no máximo $2 / 3$ da capacidade da câmara, aferição da temperatura por termômetro acessório, manutenção da porta fechada, durante o ciclo, realização de manutenção preventiva e utilização do tempo e temperatura indicados ${ }^{(1-2,7-8,12-13)}$. Também deve ser observada a disposição dos pacotes, evitando a colocação do material no centro da estufa, local identificado como pontos frios da câmara ${ }^{(10)}$.

Referente ao carregamento da estufa para o processo de esterilização, é preciso considerar dois aspectos: a confecção dos pacotes e a montagem da carga. Quanto à confecção dos pacotes, $66(65,3 \%)$ consultórios atendem às recomendações de se preparar o instrumental em caixas pequenas e em pouca quantidade ${ }^{(10,18)}$. Nas montagens das cargas, observou-se que em $58(57,4 \%)$ consultórios não ultrapassavam os $2 / 3$ da capacidade da câmara, porém em $43(42,6 \%)$ esse parâmetro não foi atendido, conforme o preconizado. A sobrecarga de materiais, na estufa, forma barreiras, para a condutividade do calor seco pelos invólucros ${ }^{(12)}$, dificultando a irradiação e/ou circulação do calor ${ }^{(18)}$, interferindo na esterilização dos artigos.

Outro fator importante na montagem da carga é a disposição dos pacotes na câmara. Nos consultórios pesquisados, em $86(85,2 \%)$ os pacotes eram acondicionados 
contrariando um ou mais critérios preconizados. Destes, $36(35,6 \%)$ se opunham a todas as recomendações, comprometendo a qualidade da esterilização.

A esterilização, por calor seco, exige cuidados como propiciar a livre circulação do ar por toda a estufa e entre os pacotes ${ }^{(2,7,18)}$. Para que isso ocorra, os invólucros devem ser dispostos na estufa obedecendo aos seguintes critérios: não encostá-los nas laterais e uns aos outros, não sobrepô-los ou colocá-los na base (utilizar apenas as prateleiras).

Outro parâmetro fundamental no monitoramento físico é a aferição da temperatura. Vale ressaltar, que a temperatura indicada no termômetro situado na base do equipamento e/ou pelo termostato não é confiável, por isso deve ser confirmada com termômetro acessório, acoplado na saída de ar, existente na parte superior da estufa, com a finalidade de indicar a temperatura interna da câmara (temperatura real) necessária para esterilização(2).

Observou-se que dos 101 consultórios odontológicos, $65(64,4 \%)$ não usavam o termômetro acessório, para monitoramento da temperatura da estufa, e apenas 36 $(35,6 \%)$ o faziam, variando de uma a três vezes o número do monitoramento, por ciclo. O controle do tempo de esterilização deve ser iniciado a partir do momento do alcance da temperatura desejada, constatada pelo termômetro acessório ${ }^{(2)}$, que deve permanecer acoplado, durante todo o ciclo.

Verificou-se que $65(64,4 \%)$ consultórios aferiam as temperaturas por outros parâmetros, sendo 64 pelo termômetro da base da estufa e um pelo controle do termostato; logo trabalhavam sem conhecimento da temperatura real alcançada pela câmara interna do equipamento, o que conseqüentemente inviabilizava o cumprimento da recomendação quanto à relação tempo/temperatura, para esterilização dos artigos.

Estudo utilizando sensores de temperatura (termopares), colocados no interior de caixas metálicas, localizados estrategicamente em seis pontos internos da câmara, demonstrou que as temperaturas registradas foram diferentes e mais baixas do que as apresentadas no termômetro embutido no equipamento ${ }^{(10)}$.

A manutenção da porta da estufa fechada, durante o ciclo é outro fator a ser observado, no momento da esterilização. Verificou-se que $88(87,1 \%)$ a realizavam. Em 13 $(12,9 \%)$ consultórios havia abertura intermitente da estu$\mathrm{fa}$, para acrescentar ou retirar instrumental. Quando isso ocorre, há prejuízo para todo o processo de esterilização, pois o artigo que foi retirado não ficou exposto o tempo necessário na temperatura preconizada, e ao acrescentar um instrumental, há queda brusca da temperatura. Nesse caso, deveria começar nova contagem de tempo a partir do momento em que o termômetro acessório acusasse a temperatura determinada. É recomendado que caso ocorra a abertura da estufa em intercorrência de extrema ne- cessidade, durante o ciclo, este deve ser reiniciado, após o alcance da temperatura convencionada ${ }^{(7)}$, observação válida apenas para o acréscimo de artigos ao ciclo.

O Ministério da Saúde recomenda que a manutenção preventiva da estufa seja feita, mensalmente, para garantir o seu correto funcionamento ${ }^{(13)}$. Nos 101 consultórios odontológicos estudados este procedimento ocorreu em apenas 18 (17,8\%). A inobservância da manutenção preventiva dificulta a deteç̧ão de problemas no equipamento, que somados à ausência de controles químicos, biológicos e físicos não sinalizam ao operador que há comprometimento no processo de esterilização, pondo em risco a eficácia da esterilização dos artigos, e consequentemente, a qualidade da assistência prestada.

Um fator que dificulta a manutenção de equipamentos esterilizantes como estufa e autoclave, relatado por alguns CD, foi a escassez de profissionais capacitados para realizá-la. Encontrou-se uma diversidade de parâmetros quanto à relação tempo/temperatura utilizada para o ciclo de esterilização. Dos 101 consultórios odonto-lógicos, apenas $47(46,5 \%)$ responsáveis pelo reprocessamento dos artigos relataram a observação do parâmetro tempo/temperatura, para a esterilização dos artigos. Desse total, 17 (16,9\%) faziam o pré-aquecimento da estufa já carregada e $30(29,8 \%)$ com a estufa vazia.

O pré-aquecimento da estufa deve ocorrer com o equipamento carregado ${ }^{(2)}$, pois ao aquecer a estufa vazia há perda de temperatura ao carregá-la, gerando a necessidade de esperar novo alcance da temperatura, para iniciar a contagem do tempo de esterilização( ${ }^{(7,13)}$, soma-se a isso, o risco de exposição ocupacional à alta temperatura, ao proceder o carregamento com a estufa pré-aquecida.

Os outros $54(53,5 \%)$ consultórios não utilizavam o parâmetro tempo/temperatura, para definir o período da esterilização. Destes, 50 (49,5\%) ligavam o equipamento, e estipulavam um "determinado tempo", constatando-se variações de 1:00 h a 4:30 h, prevalecendo o tempo de 2:00 h, para esterilização em 28 consultórios; os outros quatro $(4,0 \%)$ aguardavam o alcance da temperatura prédeterminada, que variou de $140^{\circ} \mathrm{C}$ a $200^{\circ} \mathrm{C}$, e em seguida desligavam a estufa. Ambas as práticas são contraindicadas, para a esterilização por calor seco. Exige-se observação rigorosa da relação tempo de exposição e temperatura $\left(170^{\circ} \mathrm{C}\right.$ por $1: 00 \mathrm{~h}$ ou $160^{\circ} \mathrm{C}$ por $\left.2: 00 \mathrm{~h}\right)$, a fim de assegurar a sua eficácia, e o tempo de exposição deve ser considerado apenas quando a temperatura determinada for atingida, sem incluir o tempo gasto, para o aquecimento do equipamento ${ }^{(19)}$.

O monitoramento da temperatura das estufas, utilizando termômetro Incoterm ", foi realizado somente em 94 câmaras, nas quais foi possível colocar o termômetro acessório. Considerou-se, inicialmente, como adequados, os valores de tempo/temperatura preconizados pelo Ministério da Saúde: 170 ㄷ $\mathrm{C}$ por 1 hora ou 160 ㅇ C por 2 horas $^{(1,13)}$. Destes, apenas $34(33,7 \%)$ apresentaram conformidade. 
Nas sete $(6,9 \%)$ estufas restantes, que não possibilitaram condições para o monitoramento térmico, a relação tempo /temperatura foi considerada ignorada. Destas, cinco estavam inseridas em armários embutidos e duas possuíam os orifícios, na parte superior da câmara, com diâmetros que não permitiram a colocação do termômetro.

Para fins da correlação entre os parâmetros corretos e a análise microbiológica, considerou-se também, as relações tempo/temperatura propostas: $170^{\circ} \mathrm{C} / 1 \mathrm{~h}, 160^{\circ} \mathrm{C} /$ $2 \mathrm{~h}, 150^{\circ} \mathrm{C} / 2: 30 \mathrm{~h}, 140^{\circ} \mathrm{C} / 3 \mathrm{~h}$ e $121^{\circ} \mathrm{C} / 12 \mathrm{~h}^{(20)}$. A partir da utilização destes parâmetros, o quantitativo de estufas, que apresentaram ciclos indicados, passou de 34 para 36 (35,6\%).

Objetivando-se avaliar a eficácia da esterilização, por meio das estufas de Pasteur, realizou-se a análise microbiológica com Bacillus subtilis nos 101 consultórios odontológicos. Os resultados revelaram $55(54,5 \%)$ resultados negativos e $46(45,5 \%)$ positivos. Impressionou o fato de que aproximadamente metade dos testes realizados apresentou positividade, reforçando a neces- sidade do monitoramento biológico, como prática rotineira do controle de qualidade da esterilização. Os resultados encontrados da ineficácia foram muito mais elevados do que os achados em outros estudos ${ }^{(21-23)}$.

Utilizou-se o Teste de $c^{2}$ para estudar a influência individual dos fatores intervenientes à positividade do monitoramento biológico com o Bacillus subtilis. Estes dados mostraram que os grupos, positivo e negativo, se diferenciaram, com significância estatística, para os seguintes fatores intervenientes: a não-realização de monitora-mento térmico por termômetro acessório e as relações tempo/temperatura adotadas, para os ciclos de esterilização.

Contudo, em três consultórios, apesar do cumprimento dos parâmetros de qualidade: monitoramento térmico por termômetro acessório e obediência da relação tempo/temperatura padronizada para esterilização em estufa, identificou-se positividade do teste biológico com o $B$. subtilis, constatando que outros fatores, apresentados no Quadro 1, foram determinantes para a ineficácia do processo.

Quadro 1 - Fatores intervenientes à positividade do monitoramento biológico por B. subtilis em estufas, com ciclos de esterilização indicados e monitoramento térmico por termômetros acessório nos consultórios odontológicos, do Distrito Sanitário Central de Goiânia, GO - março - 2004 a janeiro - 2005

\begin{tabular}{|l|l|l|l|}
\hline Caso & Monit. térmico & Tempo/ temp. & Fatores intervenientes \\
\hline 1 & Sim & $170^{\circ} \mathrm{C} / 1: 00 \mathrm{~h}$ & $\begin{array}{l}\text { Carga ultrapassou 2/3; pacotes dispostos encostados uns nos outros, sobrepostos e } \\
\text { utilizando a base. }\end{array}$ \\
\hline 2 & Sim & $180^{\circ} \mathrm{C} / 1: 00 \mathrm{~h}$ & $\begin{array}{l}\text { Grande quantidade de instrumental nos pacotes; carga ultrapassou os } 2 / 3 ; \text { pacotes } \\
\text { dispostos encostados uns nos outros, nas laterais, sobrepostos e no centro; } \\
\text { fechava a estufa e não-realização de manutenção do equipamento. }\end{array}$ \\
\hline 3 & Sim & $170^{\circ} \mathrm{C} / 1: 00 \mathrm{~h}$ & $\begin{array}{l}\text { Carga ultrapassou 2/3; pacotes dispostos encostados uns nos outros, nas laterais, } \\
\text { sobrepostos, no centro e base da estufa; abria e fechava a estufa e não -realização de } \\
\text { manutenção do equipamento. }\end{array}$ \\
\hline
\end{tabular}

Os dados comprovaram a importância da observação estrita dos parâmetros de qualidade preconizados, para a eficácia do processo de esterilização, em estufas de Pasteur. Para que a temperatura e o tempo recomendados sejam efetivos é necessário garantir outros fatores como: o limite de preenchimento da câmara, a disposição correta dos invólucros, o número de instrumentais por pacotes, a manutenção da temperatura pela não abertura da porta durante o ciclo e a realização da manutenção preventiva.

Estes dados confirmam o preconizado na literatura ${ }^{(3,7-8)}$, que a estufa de Pasteur requer o controle de muitas variáveis importantes, para a realização do ciclo de esterilização com qualidade, e isto a torna muito suscetível ao insucesso da esterilização. Reiteram a importância da escolha do calor úmido, na forma de vapor saturado sob pressão (autoclave), para a esterilização de artigos termorresistentes, por ser o processo mais seguro, econômico, rápido e eficiente ${ }^{(3)}$.

\section{CONCLUSÃO}

- Identificou-se predominantemente o uso da estufa, para esterilização de diversos artigos críticos odontológicos termorresistentes, para os quais é indicada como: instrumentais, brocas e limas endodônticas, assim como, para artigos termossensíveis: gazes e algodão, contrariando as recomendações preconizadas;

- Encontrou-se inadequação dos seguintes parâmetros necessários à garantia da qualidade do processo de esterilização: disposição dos pacotes na estufa, dificultando a livre circulação do calor; o não-uso de termômetro acessório, para aferir a temperatura interna do equipamento; a inobservância da relação indicada de tempo/temperatura; ausência de monitoramentos químico e biológico, para o controle da esterilização dos artigos e inexistência da realização de manutenção preventiva da estufa; 
- Os fatores intervenientes com significância estatística para a qualidade do processo de esterilização foram: ausência de monitoramento térmico da temperatura das estufas, por termômetro acessório e as relações tempo/temperatura não reconhecidas, para os ciclos de esterilização;

- Os resultados do teste microbiológico evidenciaram que a estufa de Pasteur não foi eficaz como equipamento esterilizante, em quase metade $(45,5 \%)$ dos consultórios odontológicos.

- Os responsáveis pelo reprocessamento dos artigos odontológicos possuíam idade entre 17 a 65 anos, prevalecendo o sexo feminino, tendo grande parte o segundo grau completo, e a maioria não possuía formação profissional na área da saúde.

\section{REFERÊNCIAS}

1. Brasil. Ministério da Saúde. Secretaria de Políticas de Saúde. Coordenação Nacional de DST e AIDS. Controle de infecções e a prática odontológica em tempos de AIDS: manual de condutas. Brasília; 2000.

2. Recomendações práticas para processos de esterilização em estabelecimentos de saúde: guia elaborado por enfermeiros brasileiros: Campinas: Komedi; 2000.

3. Graziano KU, Graziano RW. Limpeza, desinfecção e esterilização de artigos odontológicos e cuidados com o ambiente. In: Associação Paulista de Estudos e Controle de Infecção Hospitalar (APECIH). Controle de infecção na prática odontológica. São Paulo; 2000. p. 11-24.

4. Block SS, editor. Disinfection, sterilization, and preservation. $5^{\text {th }}$ ed. Philadelphia: Lea \& Febiger; 2001. Sterilization, disinfection, and asepsis in dentistry; p. 1049-68.

5. Brasil. Ministério da Saúde. Agência Nacional de Vigilância Sanitária. Serviços odontológicos: prevenção e controle de riscos. Brasília; 2006.

6. Thines TJ. Infection control dentistry [text on the Internet]. Bufallo; 2004. [cited 2005 May 23]. Available from: http:/ / www.ubschoolofdentalmedicinebuffalonewyork

7. Sociedade Brasileira de Enfermeiros de Centro Cirúrgico (SOBECC). Recuperação Anestésica e Centro de Material e Esterilização. Manual de Práticas Recomendadas da SOBECC. 3ạ ed. São Paulo; 2005.

8. Centers for Disease Control and Prevention (CDC). Guidelines for infection control in dental health care settings. MMWR 2003; 52 (RR17). [cited 2004 Jan 8]. Available from: http://www.cdc.gov/mmwr/preview/ mmwrhtml/rr5217al.htm

9. Conselho Nacional de Saúde. Resolução 196, de 10 de outubro de 1996. Diretrizes e normas regulamentadoras de pesquisas em seres humanos [legislação na Internet]. Brasília; 1996. [citado 2002 mar. 13]. Disponível em: http://conselho.saude.gov.br/comissao/conep/ resolução.html
O calor seco, com o uso da estufa de Pasteur, é um método de esterilização ainda muito utilizado, em Odontologia. Quando são obedecidos os parâmetros indicados o processo é eficaz, todavia, ele não é automático, depende da variável humana - o trabalhador - que realiza os ciclos, do qual são exigidos, além da qualificação profissional, consciência e compromisso ético, na sua práxis, condições essenciais para a segurança dos usuários.

Espera-se que os resultados, deste estudo, subsidiem ações educativas e de vigilância para uma prática segura de reprocessamento de artigos odontológicos, no Município de Goiânia-GO e que contribuam estimulando as Instituições de Ensino em Odontologia sobre a importância desta temática na formação da equipe odontológica.

10. Moura MLPA. Estudo sobre a eficácia do método de esterilização pelo calor seco, usando o forno de Pasteurestufa [tese livre-docência]. Rio de Janeiro: Escola de Enfermagem do Centro de Ciências Biológicas e da Saúde, Universidade Federal do Rio de Janeiro; 1990.

11. EPI INFO [computer program]. Version 3.2 for windows. Atlanta (GA): Centers for Disease Control and Prevention; 2004.

12. Brasil. Ministério da Saúde. Secretaria de Assistência à Saúde. Coordenação Geral das Unidades Hospitalares Próprias do Rio de Janeiro. Orientações gerais para Central de Esterilização. Brasília; 2001.

13. Brasil. Ministério da Saúde. Coordenação de Controle de Infecção Hospitalar. Processamento de artigos e superfícies em estabelecimentos de saúde. 2a ed. Brasília; 1994.

14. Tipple AFV, Souza TR, Bezerra ALQ. O trabalhador sem formação em enfermagem atuando em centro de material e esterilização: desafio para o enfermeiro. Rev Esc Enferm USP. 2005;39(2):173-80.

15. Tipple AFV, Souza ACS, Nakatani AYK, Carvalho MVC, Faria RS, Paiva EMM. O processamento de artigos odontológicos em centros de saúde de Goiânia. Rev Robrac. 2004; 14(37):4-17.

16. Graziano KU. Embalagem de artigos odonto-médicohospitalares. In: Lacerda RA, coordenador. Controle de infecção em centro cirúrgico: fatos, mitos e controvérsias. São Paulo: Atheneu; 2003. p. 197-211.

17. Association of Operating Room Nurses (AORN). Recommended Practices for Sterilization in Perioperative Practice Settings. Standards, recommended practices, and guidelines. Denver; 2001.

18. Brasil. Ministério da Saúde. Secretaria Nacional de Organização e Desenvolvimento de Serviços de Saúde. Manual de controle de infecção hospitalar. Brasília; 1987. 
19. Graziano KU. Processo de limpeza, desinfecção e esterilização de artigos odonto-médico-hospitalares e cuidados com o ambiente de centro cirúrgico. In: Lacerda RA, coordenador. Controle de infecção em centro cirúrgico: fatos, mitos e controvérsias. São Paulo: Atheneu; 2003. p. 163-96.

20. Perkins JJ. Principles and methods of sterilization in health sciences. Springfield: Charles C. Thomas; 1982. Dry heat sterilization; p. 286-310.

21. Aguirre-Mejía, Sánchez-Pérez, Acosta-Gío. Verificación biológica de los ciclos de esterilización. Rev ADM. 1999;66(6):151-4.
22. Prado MEM, Santos SSF. Avaliação das condições de esterilização de materiais odontológicos em consultórios na cidade de Taubaté [texto na Internet]. Taubaté; 2002. [citado 2005 maio 18]. Disponível em: www. unitau. $\mathrm{br} / \mathrm{prppg} / \mathrm{publica/biocienc/downloads/avaliacon}$ desteriliz-N1-2002.pdf

23. Baccareli JC, Silva GHS, Ribeiro MC. Biossegurança: controle de infecções e esterilização em odontologia [texto na Internet]. Campinas; 2003. [citado 2005 maio 18]. Disponível em: http://www.puc-campinas.edu.br/pesquisa/i_semana_cientifica/docentes_resumos 65DA50A746D1-495C-AAB3-7866F78736DE.pdf. 